\title{
UN NUEVO PARADIGMA DE LA TEOLOGÍA CATÓLICA. Las dimensiones histórico-cósmicas del Misterio Cristiano
}

\section{A New Paradigm in Catholic Theology: Historical- Cosmic Dimensions of Christian Mystery Um novo paradigma da teologia católica As dimensóes histórico-cósmicas do Mistério Cristáo}

\author{
Adolfo Galeano Atehortúa ofm ${ }^{\mathrm{I}}$
}

1 Licenciado en filosofía en la Universidad de San Buenaventura. Licenciado en Teología por la Universidad Gregoriana, Roma y Doctor en Teología por la misma Universidad. Actualmente profesor de teología en la Universidad Pontificia Bolivariana. Ha publicado numerosos artículos en revistas nacionales e internacionales. Entre sus principales libros están: La Iglesia y su Reforma según Y. Congar. Una eclesiología precursora del Vaticano II, Bogotá 1991; La situación humana a la luz del Evangelio. Guías homiléticas - Ciclo C., San Pablo, Bogotá 1997; La situación humana a la luz del Evangelio - Ciclo B, San Pablo, Bogotá 1998; La situación humana a la luz del Evangelio, Ciclo A, San Pablo, Bogotá 1999; La Universidad Franciscana. Evangelización y Postmodernidad, Medellín, U.S.B. 2004.

Correo electrónico: pazybienco@une.net.co

Artículo recibido el 15 noviembre 2016 y aprobado para su publicación el 10 diciembre de 2016. 
"Uno de los descubrimientos científicos más sorprendentes del último siglo y medio consiste en que el universo es una historia (story) aún en marcha” (Haught, 2009, p. 13).

"La Historia invade poco a poco todas las disciplinas" "Toda realidad experimental es por naturaleza histórica” (De Lubac, p. 150).

\section{Resumen}

El Vaticano II, la superación de la Escolástica, la revolución técnico-científica de Darwin, Einstein, Hubble, la Nouvelle Théologie, la teología científica, y todo lo que implica la llamada postmodernidad, están produciendo un cambio de paradigma en la teología católica, que implica fundamentalmente una vuelta a la historia, pero en el sentido escatológico, según la Biblia, y la asimilación de la nueva cosmología científica. El presente artículo es una presentación de ese cambio de paradigma, a la vez que destaca lo que fue el anterior paradigma predominante en la teología católica.

\section{Palabras clave}

Nouvelle Théologie, Concilio Vaticano II, Revolución científica, Postmodernidad, Escatológica, Paradigma.

\footnotetext{
Abstract

The Second Vatican Council, the overcoming of Scholastic Theology, the Nouvelle Théologie, the Scientific Theology, the Techno-scientific Revolution of Darwin, Einstein and Hubble, and some other characteristic phenomena of Postmodernity are all causing a paradigm shift in Catholic Theology. This shift mostly involves a return to History -in an eschatological sense, according to the Bible- and the assimilation of the new scientific cosmology. Therefore, the article aims to present both the previous dominant paradigm in Catholic Theology and the aforementioned paradigm shift.
} 


\section{Key words}

Nouvelle Théologie, Second Vatican Council, Scientific Revolution, Postmodernity, Eschatology, Paradigm.

\section{Resumo}

O Vaticano II, a superação da Escolástica, a revolução técnico-científica de Darwin, Einstein, Hubble, a Nouvelle Théologie, a teologia científica e tudo o que implica a chamada pós-modernidade, estão produzindo um câmbio de paradigma na teologia católica, que implica, fundamentalmente, uma volta à história, mas no sentido escatológico, segundo a Bíblia, e a assimilação da nova cosmologia científica. O presente artigo faz uma apresentação desse câmbio de paradigma, ao mesmo tempo em que destaca o que foi o anterior paradigma predominante na teologia católica.

\section{Palavras-chave}

Nouvelle Théologie, Concílio Vaticano II, Revolução científica, pós-modernidade, Escatológica, Paradigma.

La afirmación central de cuanto se trata en este artículo es que la revolución de Darwin y de Einstein y la Nouvelle Théologie han creado un nuevo paradigma para la teología cristiana. Se trata de reinterpretar las doctrinas cristianas a la luz de la evolución cósmica y biológica. El hecho es que diversos acontecimientos científicos, sociales y eclesiales se han venido produciendo desde finales del siglo XIX y durante el siglo XX, que han influido profundamente en la teología hasta el grado de producir en ella un cambio de paradigma ${ }^{2}$.

La revolución de Darwin en la biología, la de Einstein y Hubble en la física cosmológica, la nueva ciencia bíblica y el Concilio Vaticano II, a la

2 Este artículo es continuación, en cierto modo, de otro que publiqué: Un acercamiento a las corrientes de la teología católica en nuestro tiempo, en: Cuestiones Teológicas 94(jul-dic 2013) 345-374. 
vez que la superación de la worldview griega y el paradigma teológico de la escolástica que la asumía y la aparición de las teologías de la Nouvelle Théologie y la teología científica, han influido de manera determinante en este fenómeno. Por eso J. F. Haught (2009) afirma: "En el último siglo y medio de ciencia hay material suficiente para desencadenar toda una nueva revolución en teología" (pp. 60-61). A lo que agrega posteriormente:

Los desarrollos científicos actuales y lo que se espera en los campos de la genética, la robótica, la nanotecnología, la ciencia de la información, la inteligencia artificial, la biología evolucionista y la neurociencia están despertando preguntas éticas y teológicas acerca de la dirección en la cual nosotros, y la vida en la tierra con nosotros, debe ser orientada (p. 160).

O sea, ¿qué aporte puede dar la teología católica a las nuevas tecnologías que están surgiendo? Por lo que la revolución teológica se presenta a dos niveles: a nivel de la ciencia, por la revolución científica en la visión del cosmos, y a nivel de la historia, por el paso de la especulación abstracta y de una metafísica del eterno presente o del pasado a una metafísica del futuro y de la esperanza, que asume al cosmos, unida a la lectura teológica de los hechos de la historia. $Y$ es que no se trata de huir al eterno presente sino de caminar en la historia hacia el futuro que Dios nos da.

El paradigma griego de pensamiento nos ha condicionado a pensar que la eternidad espacial estática era lo perfecto y lo temporal lo imperfecto. Para el paradigma bíblico lo perfecto es lo vital, que es dinamismo. Ese mismo paradigma nos había inducido a pensar el alma como una realidad inmortal encarnada en el cuerpo, mientras que la ciencia actual nos dice que lo que llamamos alma es creada por Dios en el proceso evolutivo. Igualmente hoy somos conscientes que el cielo y el infierno no son realidades espaciales situadas arriba y abajo, y que tampoco es el espacio el que determina la realidad sino el tiempo. A todo esto se agrega que la explicación de la doctrina cristiana se ha hecho con base en la metafísica cosmológica estática, mientras que hoy se nos presenta una metafísica temporal del futuro y dinámica.

Ahora bien, ¿por qué desapareció el paradigma teológico anterior, el de la neoescolástica? Porque se basaba en una cosmología completamente superada. Por otra parte, no hay duda de que en el fondo, la nueva teología ha dado el giro a la teología católica desde la especulación abstracta hacia la realidad histórica, o sea, el paso de una teología metafísica a una teología 
histórica, más bíblica. Además, la metafísica del eterno presente en que se ha fundado la teología tradicional se descubre hoy como una huida del tiempo, de la historia y de la materia hacia una realidad celeste estática e intemporal.

La Nouvelle Théologie y la Teología Científica coinciden y se complementan en muchas cosas para dar origen a un nuevo paradigma teológico católico, pues la ciencia por sí sola no puede decirnos todo lo que acontece en el universo y darnos a conocer su sentido. La primera ahonda en el misterio de la historia en el mundo, la segunda en el misterio de la historia cósmica, que al fin y a la postre se integran, pues la historia humana es un capítulo más de la historia cósmica que comenzó con el Big Bang y porque las dos historias, la cósmica y la humana, se caracterizan por la complejidad. Podemos leer el universo pero no entendemos lo que ese escrito quiere decirnos. El universo tiene un carácter narrativo, es un libro que todavía se está escribiendo y no sabemos cuál es su mensaje completo. Porque si Dios se revela en la historia, "[...] el entero drama de la naturaleza desplegándose durante miles de millones de años también es revelación de Dios" (Haught, 2009, p. 67).

Se trata entonces de leer teológicamente la evolución cósmica. Porque "[...] desde un punto de vista teológico, la conciencia científica significa... que la aparición en medio de nosotros de la persona de Cristo no es sólo un suceso histórico, sino también un acontecimiento terrestre y cósmico" (Haught, 2009, p. 68). Además, ambas, la Nouvelle Théologie y la teología científica, son dinámicas, escatológicas, históricas. Ambas anuncian un futuro de maduración y plenitud, e integran en su visión más al tiempo que al espacio. La primera pasa de una concepción estática a una dinámica de la realidad, la otra de un cosmos y una naturaleza estática ligada a la cosmología aristotélica a una evolutiva, según la visión de Darwin y de Einstein. Pues como este último buscó explicar cómo funciona el cosmos, la teología científica cristiana intenta explicar su sentido, el sentido crístico del cosmos: "Según Einstein, es especialmente en la pregunta de por qué el universo tiene sentido donde el pensamiento científico topa con una barrera insuperable" (Haught, 2009, p. 51).

Si los teólogos de la Nouvelle Théologie interpretan el mensaje cristiano a la luz de la historia, entendida escatológicamente, los teólogos de la ciencia están empeñados en la comprensión del misterio cristiano dentro del paradigma de la nueva ciencia que pasa del metafísico-especulativo al 
paradigma empírico-experimental. Y si bien la ciencia nos muestra tres infinitos: lo inmenso, lo infinitesimal y lo complejo, según T. de Chardin, la escatología cristiana nos anuncia un futuro que supera a todo futuro, $y$ ese futuro es tanto para el hombre como para el cosmos.

Según los teólogos de la ciencia, se trata de reinterpretar las doctrinas cristianas a la luz de la evolución cósmica y biológica, o como diría T. de Chardin: “[...] cristificar francamente la evolución” (En De lubac, 1967, p. 97), ya que, "el sentido cósmico debe por tanto concluir con el sentido cristiano" (De Lubac, 1967, p.173), pues la gran causa es "la fusión explícita de la vida cristiana con la savia "natural" del universo" (p. 175). De Lubac (1967) agrega que: “Todo esfuerzo o progreso humano está destinado a ser conquistado por Jesucristo... El trabajo del mundo consiste... en consumarse por unión en un Ser preexistente" (p. 216). El cosmos es la arcilla con la que el Señor está creando al hombre en Cristo.

Los teólogos de la ciencia plantean la revisión de múltiples conceptos cristianos que están más teñidos de metafísica griega, que de revelación propiamente bíblica. Más aún, R. J. Russel (2002, pp. 3-30) piensa que la interacción entre escatología y cosmología es el tópico más importante para la actual investigación en teología y ciencia. Es la interacción entre la cosmología científica y la escatología cristiana fundamentada en la resurrección. O sea, se trata de una escatología basada en la resurrección corporal de Jesús y así en la transformación del universo en la nueva creación por Dios, realizando lo que dice Pablo: "la creación será liberada de su esclavitud a la corrupción y obtendrá la gloriosa libertad de los hijos de Dios” (Rm. 8,22.21). En otras palabras, la teología científica se plantea la posibilidad de la relación de la escatología cristiana, que habla del universo en trasformación hacia la nueva creación, la de los cielos nuevos y la nueva tierra, basada en la resurrección del Señor, con la nueva cosmología que experimenta al universo en pleno proceso de transformación y de maduración. Aunque la teología se ha servido de las filosofías abstractas y especulativas, es necesario que se sirva de la ciencia y confronte el reto que ella le representa, porque los descubrimientos científicos comprenden realidades del misterio de Dios.

Desde el Concilio de Trento venía predominando en la teología católica la escolástica, y desde la mitad del siglo XIX hasta la mitad del siglo XX se impuso la llamada neo-escolástica, gracias a lo cual el mismo tomismo se convirtió en una especie de fundamentalismo. Trento se realizó cuando 
comenzaban la llamada modernidad y la revolución científica. En cambio, el Vaticano II se llevó a cabo precisamente cuando comenzaba la era de la postmodernidad y la revolución tecnológico-informática. Asombrosamente, ni Trento tuvo en cuenta a la modernidad que empezaba, ni el Vaticano II consideró, aunque sí avizoró, a la postmodernidad que también iba a dar un vuelco a la sociedad humana.

Cuando el Papa Juan XXIII convocó el Concilio Vaticano II, todos los documentos de trabajo iniciales estaban redactados dentro del paradigma de la corriente teológica de la neoescolástica. Pero al convocar el Papa a los teólogos representativos de la teología Progresista europea y a los de la Nouvelle Théologie, se produjo un cambio verdaderamente revolucionario y el pensamiento católico se sacudió del monopolio de la escolástica y de los remanentes de la concepción moderna del mundo como totalidad autosuficiente y cerrada sobre sí misma. Gerald McCool (1989), ha escrito que: "la historia del movimiento neo-tomista moderno, cuya carta magna fue la Aeterni Patris, se terminó con el Vaticano II" (p. 30).

La revolución científica de Darwin fue adaptada en el pensamiento católico por Teilhard de Chardin y no se puede decir que haya influido directamente en el Concilio, aunque Haught (2015) dice que "no hay duda de que Gaudium et Spes refleja las ideas revolucionarias de Teilhard" (p. 47); pero después y dada la apertura del Concilio, el influjo de la revolución científica de Darwin y de Einstein se ha dejado sentir en la teología. Así que la teología católica actual ha venido saliendo de la influencia del paradigma griego de pensamiento, es decir, del eidos estático de Platón, que no está sujeto al cambio, y de la antropología y cosmología aristotélicas. Esto es evidente en la lucha de De Lubac contra la idea aristotélica de naturaleza, y de los modelos científico-naturales de verdad y de conocimiento propios de la modernidad y tiene en cuenta, a través de $\mathrm{T}$. de Chardin, los resultados de la investigación científica contemporánea. Esto ha dado origen a la llamada teología científica (Boersma, 2009, p. 10). Cabe anotar que los post-modernos están contra la razón antropológica de la modernidad y contra la idea de naturaleza, entendida como concepto normativo que encierra esencias estables. De hecho se preguntan: ¿qué tan factible es el proyecto de una sociedad civil y una cultura política basadas en la ley natural? Prácticamente la rechazan. Aún más, la modernidad fue el predominio de la teoría sobre la praxis. La postmodernidad es lo contrario: primero los hechos constatables y luego la teoría. 
Por lo que a la influencia de la ciencia bíblica actual en la teología, se trata de abandonar una lectura de la Biblia según el paradigma inmóvil del pensamiento griego y hacer esa lectura según el mismo paradigma bíblico dinámico e histórico. Ahora bien, hay una coincidencia feliz de la revolución científica con el pensamiento bíblico. No en vano Einstein era judío, fue instruido en la Biblia y se sentía cautivado por la figura de Jesús. Hay un desplazamiento del espacio al tiempo y de lo estático a lo dinámico, expresado ya por Newman (1997): "Vivir es cambiar; y ser perfecto es haber cambiado a menudo" (p. 66).

\section{EL VATICANO II}

"La Nouvelle théologie, como corriente progresista de la Iglesia, se esforzó finalmente por asegurar su legado mediante el Concilio Vaticano II". (Boersma, 2009, p. 10).

El Vaticano II implicó una gestación cuidadosa y dolorosa. En él confluyen las dos tendencias principales de la teología católica: la agustiniana y la escolástica tomista, en tres vertientes: la jesuítica liderada por Rahner, que intentó una reconciliación del tomismo con la filosofía moderna en cuanto afirmación del sujeto; la del tomismo renovado de Chenu y Congar, el cual hablaba de la "revolución albertino-tomista", e insistía con Chenu en la interpretación histórica de Santo Tomás. Chenu hablaba de la propensión del hombre hacia el sobrenatural, que el tomismo llamaba la "potencia obediencial", de la inadecuación de la moderna doctrina social de la Iglesia, construida sobre el presupuesto de una ley natural accesible a la recta razón y que partía de principios abstractos. Igualmente rechazaba la eclesiología de la "societas perfecta". La tercera vertiente tomista era el neotomismo, liderado por Garrigou-Lagrange. La corriente agustiniana se presentaba con un enfoque escatológico, con énfasis en el misterio de la Cruz y con una antropología pesimista por su énfasis en el pecado. La tomista era de carácter encarnacionista y con una antropología optimista.

La corriente agustiniana estuvo representada en el Concilio por los teólogos de la Nouvelle Théologie, de la cual hicieron parte, entre otros, Henry de Lubac y Ratzinger. Después de la Reforma y a causa del jansenismo, la teología agustiniana había sufrido una cierta falta de aceptación en la 
Iglesia católica. Ratzinger, en cambio, se afianza en el agustinismo, sobre todo bonaventuriano, y reprocha a los tomistas, incluido el mismo Santo Tomás, que acentuaron la autonomía del mundo y de la razón humana. Se distanció también de la tradición tomista que había elaborado la eclesiología de la Iglesia como sociedad perfecta y rechazó claramente la neoescolástica.

Así que tres corrientes teológicos laboraron el Concilio. La neoescolástica redactó los primeros documentos de trabajo. Después vinieron otras dos corrientes que aportaron la renovación. Está la teología progresista europea liderada por Karl Rahner, que aportó la adecuación de la Iglesia a la modernidad, ante la cual la Iglesia había mantenido una actitud de desconfianza y rechazo; pero la asumió, sin embargo, cuando la modernidad estaba entrando en agonía y aparecía un nuevo contexto socio-cultural, la llamada postmodernidad. Está también la corriente teológica de la Nouvelle Théologie, liderada por Henri de Lubac y que va a ser la más decisiva para hacer que el Concilio volviera a las fuentes de la Sagrada Escritura y de los Padres y asumiera los progresos teológicos que venían desde Newman, pero que también colocara a la Iglesia en la dirección postmoderna, como lo anota Milbank (2004, p. 289). Lubac atacó, en teología, dos conceptos básicos de la modernidad y rechazados por la post-modernidad: la razón y la naturaleza, y, en conclusión la idea de una ley natural accesible a la recta razón. Por lo demás, todo el movimiento de la Nouvelle Théologie asumía a la historia como estructura fundamental, algo muy propio también de la post-modernidad.

Por eso, Rahner y De Lubac representan dos visiones teológicas que pusieron al Concilio en la articulación entre la modernidad y la postmodernidad. Las dos tendencias confluyen en el Vaticano II que representa aspectos contradictorios, en este sentido. Como lo anota Milbank, Vaticano II abraza la modernidad democrática de la política liberal; representa un retorno a los Padres y al Santo Tomás auténtico; y reelabora ciertos aspectos de la neo-escolástica.

Es muy interesante que las dos obras de teología católica del siglo XX, más influyentes y determinantes, se produjeron en las dos escuelas teológicas que dieron origen a la Nouvelle Théologie: El Surnaturel: Etudes historiques (1946) de Henri de Lubac, de la escuela de los jesuitas en Lyon-Fourviere, y Une Ecole de théologie: Le Salchoir (1937) de Marie-Dominique Chenu, de la escuela de los dominicos en Le Saulchoir. 


\section{LA NEO-ESCOLÁSTICA. RESPUESTA CATÓLICA A LA MODERNIDAD}

"La historia del movimiento neo-tomista, cuya carta magna fue la Aeterni Patris, tuvo su fin con el Vaticano II". Gerald McCool.

Con la Aeterni Patris, de 1879, el papa León XIII buscó dar a la neo-escolástica su carácter definitivo, en una óptica de principios inmutables y universales y responder al reto que presentaba la modernidad con su tarea de secularizar la sociedad. Fue así como la escolástica se convirtió en el paradigma oficial del pensamiento de la Iglesia, pero a partir del Vaticano II ha perdido el estatus de ideología privilegiada. El hecho es que esta teología cayó en lo que Geral McCool llama una estéril "teología de conclusión". Esto implicaba el estancamiento y la objetivización de los misterios revelados en un esfuerzo por encerrarlos dentro de un sistema científico deductivo y a-histórico.

En efecto, los cambios globales que se dieron en los años 60, entre los cuales estuvo el Vaticano II, que reformó la Weltanschauung católica y sacudió su fundamento intelectual que era la filosofía neoescolástica, marcaron el final de esta corriente teológica. Pero, ¿cómo se originó esta teología y cuál era su orientación y su método? Voy a hacer una sucinta historia, basándome en la presentación que hace Gerald A. McCool (1989).

Hacia 1853, los jesuitas asociados con la Civiltá Cattolica iniciaron su campaña para la restauración del tomismo como único sistema de filosofía para las escuelas católicas. Pensaban ellos que solo el tomismo podría estructurar una sana teología. Los demás métodos de filosofía y teología debían ser removidos. En 1853, Matteo Liberatore se unió al grupo de jesuitas de la Civiltá Cattolica, con los cuales trabajaba también Joseph Kleugen, del colegio germánico dirigido por los jesuitas. Antes, Taparelli había propuesto que la doctrina de Santo Tomás fuera restaurada como el principio de unidad en la enseñanza de la Sociedad de Jesús. Esto fue aceptado por la congregación general de la sociedad en 1854. En 1858 Liberatore, Taparelli, Sordi, Curci y Kleugen prepararon una Ordinatio Studiorum, incorporando sus ideas, y fue hecho obligatorio para la Compañía. Entre 1853 y 1870 Kleugen publicó su Theologie der Vorzeit, y entre 1860 y 1863 su Philosophic der Vorzeit. Estos autores se propusieron demostrar que Descartes, Kant, Hegel, Rosmini, Gioberti, y los ontologístas, filósofos todos de la modernidad, estaban errados. Era necesario demostrar cómo 
el tomismo puede fundamentar una filosofía y una teología científicas sin caer en los errores de las filosofías post-cartesiana. Así que el neo-tomismo lanzó su ataque contra el romanticismo católico y la teológica post-Kantiana.

El primer volumen de la teología der Vorzeit de Kleugen fue publicado en 1853, el mismo año cuando los jesuitas de la Civilta Cattolica iniciaron su campaña de restauración del tomismo. La palabra Vorzeit se refiere a los viejos tiempos, aquellos pre-modernos. Para Kleugen, Theologie de Vorzeit significaba, en efecto, la teología pre-cartesiana. Tres volúmenes de la obra están dedicados a la exposición de la teología católica tradicional y a los enfoques de Hermes, Hirscher y Günther. Para Kleugen, la diferencia entre las teologías escolástica y moderna estaba en los métodos empleados. La segunda parte de la obra se dirige a la necesidad de establecer el método teológico.

La epistemología y la metafísica del ser de Kleugen debían más a Suárez que a Santo Tomás. Identificó la escolástica de Francisco Suárez con el pensamiento de Santo Tomás, cuando en realidad Suárez "era ya un pensador moderno, quizás más auténticamente que Descartes" (McCool, 1989, p. 195). El escolasticismo barroco era realmente la "vieja" teología que Kleugen quería restaurar. De esta manera, la teología especulativa católica se convirtió en una "teología de conclusión", cuyo propósito era derivar ciertas conclusiones teológicas de sus primeros principios revelados. En consecuencia, la teología católica de conclusión se convirtió en una tarea especulativa estéril. Sus conclusiones se hicieron más y más remotas de la vida concreta ordinaria de los cristianos.

Como Suárez, Kleugen no tenía sentido del desarrollo histórico. No demostraba conciencia del rol del desarrollo cultural o de las diferentes estructuras conceptuales en la historia del pensamiento. Su estructura conceptual era esencialmente la del escolasticismo de la era post-reformada, que era dependiente servilmente de Aristóteles, y muy relacionado con el naturalismo de la Ilustración. La teología escolástica era, pues, una ciencia aristotélica. Otra deficiencia del escolasticismo era su carencia de sistema sobre todo en teología moral, lo que produjo un juridícismo mosáico. El camino hacia el fin sobrenatural del hombre caído según la Summa Theologiae era la vía de las virtudes. La tarea del Redentor y de los sacramentos era la justificación y la santificación. Kleugen ignoraba la teología de Tubinga en la que primaba la naturaleza orgánica del Reino de Dios, su realización histórica a través de las vicisitudes del tiempo, el lugar de la tradición viva 
en la Iglesia y el papel del Espíritu Santo como fuente viva de unidad de la Iglesia. La comunidad, como la historia, tenía poco interés para Kleugen.

Los teólogos escolásticos de la era post-reformación como Cano, Suárez, Vásquez, de Lugo, aplicaron el método de Santo Tomás a los nuevos problemas que se presentaron con el surgimiento de la teología de controversia y la positiva. Así que la definición de teología de Lugo, que llegó a ser común en la escolástica post-reforma, fue: "La ciencia que deriva sus doctrinas de la fe con la ayuda del pensamiento" (citado en McCool, 1989, p. 187). Para Kleugen, los teólogos modernos tales como Hermes, Hirscher y Günther, separaron la teología dogmática de la teología práctica y la especulativa. Así como la filosofía post-cartesiana había resquebrajado la unidad de pensamiento y ser, que la vieja filosofía había preservado, así el método post-cartesiano había sacudido la unidad intrínseca de teología dogmática, práctica y especulativa. El De Locis Theologicis de Melchor Cano era el ejemplo supremo de la aplicación del método escolástico a los problemas de la teología positiva. En el quinto volumen de su Theologie der Vorzeit, Kleugen presentó una exposición del método teológico de Hermes y, en contraste con él, presentó su propia concepción de la naturaleza de la teología positiva escolástica. Hermes consideraba el approach escolástico a la teología positiva completamente anti-científico. Por eso su razonamiento silogístico empezaba con una serie de juicios primordiales o primeros principios revelados; en cambio la teología científica no era la deducción de conclusiones especulativas a partir de primeros principios. Era la reunión positiva de un cuerpo de verdades individuales desde sus fuentes históricas.

A pesar del deseo de los padres conciliares del Vaticano I por abolir la intervención innecesaria de las disputas teológicas, la teología escolástica tuvo una gran influencia en la redacción del Dei Filius. La preparación del primer esquema conciliar sobre la fe había sido confiado a Johannes Baptist Franzelin del Colegio romano. Este no era miembro del equipo de los jesuitas de la Civilta Cattolica y no tomó parte en la campaña por la restauración del tomismo como sistema unitario de filosofía y teología, pero compartía la visión escolástica de Perrone. Dividió, como también lo hizo Kleugen, a los teólogos del siglo XIX contrarios a la ortodoxia católica, entre fideístas y semirracionalistas. La redacción sobre la fe de Franzelin fue revisada, aunque se mantuvieron sus ideas.

Como lo ha señalado H.J. Pottmeyer, el teologumeno de la escolástica de la post-Reforma relativo al posible estado de "natura pura" influenció 
fuertemente el tratamiento de la gracia y la naturaleza del Vaticano I y tuvo consecuencias inmediatas para la teología de fe y razón. Este teologumeno, al defender la posibilidad de un estado de natura pura, que no representaba el pensamiento de Santo Tomás, influenció no solo esta teología sino también la interpretación de su significado de muchos padres conciliares. Muchos de los prelados del Concilio interpretaron la enseñanza católica en gracia y naturaleza de acuerdo con el teologumeno de la escolástica barroca. Este teologumeno no sólo afectó la redacción de Dei Filius y su interpretación, sino que también fortificó el desarrollo de la teología no-histórica científica aristotélica en la Iglesia post-conciliar. Esta teología centró su atención en las posibilidades metafísicas de una naturaleza humana abstracta, prescindiendo de su fin sobrenatural. Como teología aristotélica de la naturaleza, no estaba interesada con el orden histórico. El conocimiento humano era considerado en abstracto y caía en dos divisiones: natural y revelado.

En cuanto a la encíclica Aeterni Patris, quien preparó un esquema preliminar fue Liberatore, y probablemente también Kleugen preparó otro. De todas maneras la aproximación no-histórica a la filosofía y a la teología que caracteriza la encíclica es muy similar a la aproximación de Kleugen en su Die Theologie der Vorzeit. Un análisis de Aeterni Patris revela el compromiso de León XIII con el ideal neo-tomista de la filosofía escolástica como medio necesario para apalancar los ministros de la Iglesia para su apostolado en el mundo moderno. La neo-escolástica aportaba la armadura de la Weltanschauung católica, la estructura de ideas sobre la que se debía edificar la cultura católica.

\section{EL FIN DEL PARADIGMA NEO-ESCOLÁSTICO-}

"Von Balthasar cree que la teología neoescolástica, inconscientemente, conspiraba con el racionalismo de la Ilustración para producir una forma católica de deísmo" (Mongrain, 2002, p. 70).

Entre todas las críticas que se pueden hacer a la neo-escolástica, una muy decisiva es que el paradigma de esta teología estaba fundamentado en una concepción científica, la aristotélica, completamente superada por la nueva ciencia, la que viene de Darwin y Einstein. Además, la autoridad de que gozaba Aristóteles estaba consagrada en la síntesis tomista-escolástica, en la 
que el motor inmóvil aristotélico se funde con el Dios-ágape y patético de la Biblia. Era necesario liberar la visión cristiana de Dios de las garras griegas. Pues aquí, dice Haught (2009), "Dios es presentado como una omnipotencia sin amor, una inteligencia sin compasión, un absoluto sin relacionalidad, una eternidad purificada de temporalidad o una inmutabilidad esterilizada de todo drama interior" (p. 77).

Fue en el siglo XX, sin embargo, cuando se presentó una crítica y una reacción teológica contra la neo-escolástica. Los antecesores más influyentes de esta reacción fueron J. A. Möhler (1796-1838) de la escuela católica de Tubinga, J.H. Newman (1801-1890) y los tradicionalistas franceses Felicité de Lamennais (1782-1854) y Louis Bautain (1796-1867). Aquí empezó la rebelión contra la objetividad y el método científicamente deductivo de la teología escolástica.

La crítica ha sido amplia y devastadora. Balthasar (1939), por ejemplo, se preguntaba ya desde el año 39 del siglo XX: ¿Fue el escolasticismo una vía falsa, con su "racionalización" del dogma, su débil dialéctica y su demasiado ingenua lógica secular? En el mismo artículo, Balthasar hace una evaluación y una comparación, bien de la teología patrística, bien de la escolástica. Advierte que tanto la patrística como la escolástica tienen sus fortalezas y sus peligros. La tentación de la escolástica es racionalizar el orden sobrenatural mediante un esquema aristotélico de pensamiento, y el de la patrística era huir del orden natural a un platonismo místico.

Desde el punto de vista de la escolástica ese énfasis estaba en considerar la persona de Jesús en su facticidad terrena y humana, contra la imagen de Cristo cósmica y universal de la era patrística. Se acentuaba lo "positivo" de la jerarquía eclesiástica. El mundo en el que ha tomado lugar la encarnación es verdaderamente mundo mundano: no una sombra o copia simbólica de un mundo universal más alto, espiritual e ideal. Así que la escolástica intentó clarificar la tensión no resuelta entre Dios y el mundo, pasando de Platón a Aristóteles. Esto significaba reemplazar el esquema de participación por el esquema de efecto a causa. En lugar de la Gran Cadena del Ser platónica, surge ahora el cosmos cerrado en sí mismo y en el cual cada cosa individual posee su valor y su dignidad. El peligro de esta posición es terminar en un sistema inmanente y puramente filosófico. El énfasis en el fundamento natural tiene el peligro de dividir al ser en dos mundos que no se comunican: una zona natural y otra sobrenatural. 
Otros dos autores, particularmente críticos de la neo-ecolástica: De Lubac y J. B. Metz. El primero hizo su crítica antes del Vaticano II. El segundo es posterior al Concilio, pero al principio estuvo muy ligado a Rahner y a la neoescolástica; posteriormente se orientó por la teología política bajo la influencia de Moltmann.

\section{HENRI DE LUBAC-}

"El Sobrenatural fue un golpe intencional a la comprensión neoescolástica de la razón y de la gracia, como también a la concepción neo-escolástica de la filosofía y la teología y a la relación entre ambas"

(Milbank, 2005, pp. 3-4)

En un artículo publicado durante la segunda guerra mundial, De Lubac comparaba la teología neo-escolástica con un museo. Sugería que los teólogos católicos divagaban en teología como en un museo donde todo está bien organizado y catalogado, en el que se sabía definir todos los términos y donde se tenía una respuesta para todas las objeciones. Allí todo era oscuro para los laicos, pero para los clérigos todo era claro y muy bien explicado.

Es muy significativo que una de sus mayores oponentes fue Reginald Garrigou-Lagrange (1877-1964). Según Fergus Kerr, éste fue uno de los primeros en atacar el Sobrenatural De Lubac. Era amigo del régimen de Vichi y simpatizó durante un tiempo con la Acción Francesa. Fue amigo del embajador de Vichy en el Vaticano, quien aseguró a su gobierno que la Santa Sede no tenía objeciones a la legislación anti-judía del régimen de Vichy.

El Sobrenatural De Lubac no es solo un análisis histórico y una crítica de la noción de "naturaleza pura" contra la cual realiza el esfuerzo por la "supernaturalización de lo natural", según expresión de Millbank (2004, pp. 285-ss), sino que es también una crítica de la noción de teología, y tiene sus reservas sobre los logros medievales, incluidos los de Santo Tomás, y es un análisis de las causas del exilio moderno de la teología y sus consecuencias culturales. Critica el hecho de que los teólogos en la era de la modernidad cedieron el mundo al secularismo por ese dualismo que creaban con la teoría de la "natura pura". 
J. Milbank (2004) dice que el Sobrenatural “[...] es el texto teológico clave del siglo veinte" (p. 3). Es la mejor respuesta y un ataque al secularismo moderno que promueve una cultura "etsi Deus non daretur", como si Dios no existiera, y el hombre lograra construir una sociedad plena con sus solas fuerzas naturales. Se propuso, entonces, la superación de una teología insípida, seca y el retorno a los padres y a la Sagrada Escritura. El meollo está en la recuperación del sobrenatural en la teología católica y el rechazo de la antropología aristotélica, de la neoescolástica, del inmanentismo de la modernidad, de la teología del progresismo europeo y de la teología de la liberación. Pero, además, la repristinación en la Sagrada Escritura, que la neo-escolástica no desconoció pero sí infravaloró frente a la especulación metafísica, ha puesto de relieve el paradigma hebreo de pensamiento, que es histórico, escatológico y temporal, frente al paradigma griego que es a-histórico, cíclico y espacial.

De Lubac sintió que Santo Tomás introdujo un acercamiento, un método, una serie de presupuestos que hicieron posible que posteriores pensadores malinterpretaran su pensamiento. Analiza dos movimientos: la introducción del pensamiento de Aristóteles y el paso del simbolismo patrístico a la dialéctica. Describe la tensión y la contradicción entre la imagen patrística de Dios y la "naturaleza" de Aristóteles. Con Santo Tomás, estas dos concepciones se mezclan sin poder decirse si se combinan o chocan una con otra, ni cuál de las dos se impone a la postre. Puesto que Santo Tomás intentó dar al deseo de ver a Dios un fundamento en la naturaleza, definida en términos aristotélicos, su pensamiento contiene una tensión interna.

Para De Lubac este esfuerzo de Santo Tomás dejó abierta la puerta para que pensadores posteriores redujeran los deseos de la naturaleza a algo que es naturaleza en sentido aristotélico. Compara a San Anselmo con Santo Tomás, pues la tarea del primero fue un paso decisivo en la transformación del agustinismo, ya que transformó la comprensión espiritual agustiniana en una comprensión dialéctica. Santo Tomás, por su parte, intelectualizó y naturalizó a San Agustín. Si se extreman las posiciones de Santo Tomás se hace difícil mantener el sobrenatural y el carácter de gratuidad absoluta de la visión beatífica. Así que las posiciones de los teólogos medievales llevaron a una distorsión del pensamiento agustiniano, que posteriormente será exagerado de tal manera que llegó a amenazar la ortodoxia y a provocar la reacción de separar el sobrenatural de la naturaleza, mediante la teoría de la "natura pura". 


\section{J. B. METZ.-}

"En oposición a Rahner, Metz teme que toda la historia de Dios con la humanidad sea puesta en entredicho" (Vorgrimler, 1998, pp. 186).

Empieza por afirmar que en Santo Tomás aparece una nueva forma de pensar: la antropocéntrica de la modernidad opuesta a la cosmocéntrica de los griegos. Esto hace de Santo Tomás un precursor del pensamiento moderno. A pesar de todo, "Tomás, sobre todo en los pasajes filosóficoanalíticos de su obra [...], queda muy ligado a la concepción cosmocéntrica del ser" (Metz, 1972, p. 113). De hecho, Metz distingue la estructura mental griega o el modelo conceptual griego que califica de cosmocéntrico, objetivista, espacial, determinado por la ratio universalis estática, y en el que el hombre aparece como un fragmento del ser cósmico a-personal o sea determinado por la naturaleza cósica, y el ser se ve en la dimensión cósica, pre-personal y estática. Luego está el modelo conceptual moderno que califica de antropocéntrico, pero que también es subjetivista, y la estructura mental bíblica que es histórica.

Según Metz, en Santo Tomás se da un cambio en la concepción del ser gracias al aporte del cristianismo, porque es propio de la forma del pensamiento cristiano el que "doblega todo pensamiento a la obediencia de Cristo" (2 Cor. 10,5). Es decir, "es el cristianismo mismo el que dispone y prepara la metafísica para si” (p. 126). No se ve, sin embargo, que logre mostrar que Santo Tomás realmente realice un cambio de la perspectiva espacial griega hacia la perspectiva histórico-temporal bíblica, o que la comprensión histórica propia de la Biblia sea la tomista.

No hay duda que muestra el cambio metafísico operado por Santo Tomás con respecto al pensamiento metafísico griego, pues "es Tomás quien, por primera vez, rompe la concepción cosmocéntrica de la sustancia" (p. 84), ya que en él, "por vez primera, se inicia una valoración del individuo fundamentada en sus bases ontológicas" (p. 84), valoración del individuo que es obra del cristianismo y que Santo Tomás incorpora al pensamiento aristotélico-griego. Pero, se debe entender que el pensamiento bíblico no es metafísico como sí lo es el griego y no se puede comprender la estructura mental histórica bíblica desde la metafísica griega, o pretender incorporar la primera dentro de la segunda. Claro que Metz reconoce que "una demolición del esquema conceptual estático-espacial referente al ser del mundo y, a la 
vez, una [...] estructuración de un esquema primordialmente histórico [...]" (p. 90) apenas sí aparece germinalmente en Santo Tomás, y "el pensamiento tomasiano, a pesar de su originalidad, permaneció inmerso en el horizonte conceptual griego" (p. 110).

Con todo, Metz reconoce que Santo Tomás piensa con conceptos griego-aritotélicos pero desde la perspectiva bíblica. Por eso, supera la concepción dualista griega del hombre, pues no piensa el alma del hombre cosmocentricamente sino antropocentricamente. Así también, no concibe la trascendencia de manera cósmico-espacial y estática objetivista, sino que la ve en la dimensión de lo infinito, la trascendencia hacia Dios. Santo Tomás no llega a la trascendencia personalista que aparece tan clara en San Agustín: el yo del hombre que se trasciende en el Tú de Dios. Santo Tomás es, sin duda, una figura de transición entre la teología monástica y su sentido sacramental del mundo, y los desarrollos del siglo XIV que produjeron tensiones y contradicciones entre la naturaleza y la gracia, la razón y la fe, y el rechazo de Aristóteles. Él presenta su propio proyecto explicando que la fe es la continuación de la filosofía de los filósofos gentiles en su búsqueda de la sabiduría.

\title{
K. RAHNER, EL TEÓLOGO DE LA MODERNIDAD EUROPEA
}

\begin{abstract}
"A Rahner se le ha reprochado... que no habría rebasado el nivel del teorizador idealista... En este esquema, el tú, el nosotros y la historia quedarían envueltos en la niebla” (Vorgrimler, 1988, pp. 177-178).
\end{abstract}

Se ha dicho antes que Rahner aportó la adecuación de la Iglesia a la modernidad, esto porque él es un teólogo de la modernidad. Pero las críticas no son pocas: que tiene poco en cuenta la Sagrada Escritura y los Padres, que en su Curso fundamental sobre la fe su doctrina sobre la Trinidad es pobre y que, en esa obra, poco se refiere a María, la Madre del Señor; también que su pensamiento es ambiguo y que como Santo Tomás de Aquino, Suárez y Kleugen, desconoce la historia. Para muchos, su teología es un anacronismo, dado el fin de la modernidad y el surgimiento de la post-modernidad. Podría considerársele como el teólogo en el que culmina la modernidad de la teología católica. Una modernidad que asume la neoescolástica y la 
integra con el pensamiento de Kant y Heidegger, pero que no llega a la postmodernidad de la Nouvelle Théologie, que se orienta por la historia entendida escatológicamente. Se le critica el haber acomodado la cristología a las demandas de una antropología independiente de la Revelación y el hecho de que su "sujeto trascendental" perpetúa el dualismo modernista de la neo-escolástica.

Milbank lo coloca como puente entre la modernidad y la postmodernidad y lo identifica como alguien simultáneamente conservador y liberal, precisamente por su arraigo en la neo-escolástica y su posición frente a la tesis de la "naturaleza pura", de la que no se desprende totalmente. Esto en cuanto su orientación conservadora, porque en cuanto a su liberalismo tiene que ver con su kantismo modificado y la influencia que tiene de Heidegger.

Ratzinger subraya que Rahner está muy condicionado por el escolasticismo de Suárez o del Barroco. La argumentación de Rahner descansa en su teología trascendental inspirada en el pensamiento de Kant, Joseph Maréchal, y Heidegger, además de la escolástica. Es un pensamiento que ejemplariza la transición entre la metafísica tomista y la modernidad.

Su diferencia con De Lubac es grande. Este no es sistemático; Rahner lo es en gran parte. El primero se centra en la eclesiología; Rahner en la antropología. La base de De Lubac son las Escrituras y los Padres; la de Rahner es la filosofía moderna. Interpreta a Santo Tomás a partir de Kant y de Heidegger y sigue en gran parte a Suárez; mientras, De Lubac es bastante crítico de Suárez y de Santo Tomás y a su vez critica la interpretación suareziana de Santo Tomás.

Los contrastes con otros grandes teólogos católicos que hicieron el Concilio no paran aquí. Como lo consigna Millbank, Ratzinger reconoce que él y Rahner viven en dos planetas teológicos diferentes. Ratzinger manifiesta un anti-kantismo o anti-modernidad en la línea de De Lubac y Balthasar. Además, parece más radical y más post-moderno, pues basándose en la visión de los Padres, formula una teología de la historia que supera la dicotomía sujeto-objeto mediante la integración de la fe y la razón, la revelación y la reflexión lógica. Se interesó por recobrar el sentido del desarrollo de Newman articulado históricamente. En cambio Rahner es más abstracto, se basa en un modelo trascendental evolucionista, que asume al Logos como mediador. 
Rahner parte de la subjetividad del ser humano, su horizonte espiritual infinito e individual, y continua con la autorevelación gratuita de Dios. La Nouvelle Théologie comienza con Dios. En Rahner hay un problema metodológico al construir su teología partiendo "de abajo", de la subjetividad humana, pero de manera a-histórica. Deja la impresión de que la historia y la sociedad son manifestaciones de algo ya presupuesto. No cabe duda que Rahner está muy condicionado por las categorías a-priori de Kant. Para él los aspectos sociales de la salvación son algo adicional al individuo y ve a la Iglesia como estructura mediadora porque mediante ella se transmite la salvación. Para De Lubac, en cambio, la Iglesia es el contenido mismo de la salvación y la existencia humana no pertenece a la metafísica sino que es algo histórico.

Una secuela de la modernidad, del neomarxismo, de la teología política, y de la teología de Rahner ha sido la teología de la liberación latinoamericana. Por esto mismo languideció con la crisis de la modernidad y el desplome del marxismo. La influencia de Rahner en los teólogos de la liberación es algo muy destacado por Millbank. En efecto, estos teólogos intentaron reinterpretar el cristianismo en términos de la razón laica y consideraron la salvación de manera muy individualista, pues la realidad social aparece como algo agregado y suplementario al individuo. De la teología de Rahner y del marxismo toman su idea de salvación que se convierte en una utopía de liberación de las opresiones sociales. Más aún, dejan de lado el contenido eclesial de la salvación y la presentan como una "opción ética privada". Según Millbank (2004), estos teólogos "han abrazado con entusiasmo la sociología laica porque rechazan el historicismo no extrencista de Blondel, Lubac y Von Balthasar y aceptan la metafísica ahistórica rahneriana de la subjetividad humana" (p.308). Es esta aceptación de la metafísica a-histórica y el desconocimiento de la historia lo que hace a la teología de la liberación perteneciente a la modernidad.

\section{LA TEOLOGÍA CIENTÍFICA- UNA TEOLOGÍA DE LA POSTMODERNIDAD}

"Einstein creía que las descripciones científicas no pueden satisfacer nuestra necesidades humanas, que hay algo esencial en el "ahora" que queda... fuera de los dominios de la ciencia”. R. Carnap. 
Una de las preguntas fundamentales que el nuevo paradigma teológico se hace es: ¿Qué relevancia tienen para la fe cristiana los grandes descubrimientos de la física, la biología y la cosmología? El hecho es que la ciencia está poniendo ante nosotros una nueva realidad cósmica ante la cual la teología cristiana debe reflexionar el sentido. Se impone la superación de la teología a-cósmica tradicional. Basta pensar en uno de los grandes descubrimientos del siglo XX "que el cosmos es un relato todavía abierto, la creación no ha concluido" (Haught, 2009, p. 78). El cosmos tiene un carácter dramático o narrativo. Así que la nueva teología se propone liberarse del paradigma griego, una liberación que ya estaba in ciernes en la doctrina de la Resurrección que aniquiló la idea griega del eterno retorno de lo mismo, y en la doctrina trinitaria que borró la idea del ser eterno estático y solitario griego. Dios es una comunión de amor.

La cosmología de Einstein, quien concibe la realidad de forma dinámica, y que es llamado el "descubridor de los misterios del átomo y del universo", es el marco de la revolución científica y tecnológica de los siglos XX y XXI, que ha producido la llamada postmodernidad. Esto por lo que se refiere al macrocosmos, porque también la mecánica cuántica, que se inició a comienzos del siglo XX, nos alertó de que existía, en la realidad micro, un mundo misterioso, complejo, aleatorio, incoherente y caótico, lleno de incertidumbres y paradojas.

Para explicar lo inexplicable se ha inventado la teoría del azar, por el que un suceso fortuito está en el origen de todo. La teoría del caos o del quántum nos dice que el proceso diario del mundo, y no sólo las raíces subatómicas del mundo, tiene un comportamiento impredecible y nomecánico. En este campo, como en la revolución francesa, en el nazismo y en el marxismo, se levantan las voces de los científicos ateos, desde Jacques Monod hasta Richard Dawkins, Carl Sagan y Daniel Dennet, Sam Harris, Christopher Hitchens, Michel Onfray, y John Allen Paulos que anuncian el triunfo sobre el cristianismo, pues según ellos "un ciego azar" en el corazón de la evolución contradice la fe en el Dios bíblico creador y providente. Monod confiesa: "El azar solo es la fuente de toda innovación, de todo lo creado en la biosfera. Puro azar, absolutamente libre pero ciego, está en el camino del estupendo edificio de la evolución [...]". Y concluye: “[...] al fin el hombre sabe que está solo en la insensible inmensidad del universo del cual él ha surgido solo por azar". A lo que responde Haught (2009): "Si la ciencia fuera nuestra única vía hacia la intelección verdadera y completa, 
deberíamos concluir que lo que espera al cosmos es la pura nada" (p. 91). Tal teoría es la afirmación de la muerte, porque si el universo va hacia un estallido final, ¿qué es eso sino el triunfo de la muerte? A esto responde el cristianismo con el triunfo de Jesús sobre la muerte en su Resurrección, un triunfo de consecuencias cósmicas.

Además, ¿es ciego e impersonal el inmenso dinamismo cósmico? La teología católica lee en él una obra de amor infinito. A la entropía cósmica, a la catástrofe cósmica o sideral, y al mal de la historia, la Iglesia responde con el anuncio de la obra creadora y salvadora del Señor, porque el cristianismo es el que ofrece a un cosmos que aparece como un abismo silencioso, indiferente y frío, un sentido y una razón de ser. Por lo demás, la teología científica asocia la acción divina a la indeterminación cósmica, puesto que Dios permite a su creación "hasta cierto punto 'hacerse a sí mismà por medio de la aleatoria exploración de la contingencia" (Polkinghorne, 2000, p. 118). ¿No ocurre lo mismo en la historia? Dios deja al hombre actuar libremente.

El hombre, en nuestro siglo, se presenta como un ser histórico y como parte de la historia cósmica, es decir, somos parte de un proceso históricocósmico y vivimos al ritmo cósmico, al ritmo de los astros, en comunión con el universo. En palabras de A. Peacocke (2008): "somos polvo de estrellas convertido en personas" (p. 125). Todos los interrogantes sobre el cosmos confluyen en el ser humano, en él se explican el Big Bang, la evolución cósmica o cosmogénesis, según Teilhard de Chardin, la radiación cósmica de fondo, la sopa cósmica de quarks, las galaxias, los asteroides, meteoritos y cometas, el sol y todas las estrellas. El hombre hace parte del drama del mar y las estrellas, pues la cosmogénesis como la antropogénesis son un drama histórico.

El hombre como ser pensante es la floración del cosmos. Él tiene una matrix cósmica, viene de un largo drama cósmico, porque el universo fue el que engendró a los seres humanos. De aquí que sea necesaria una nueva "worldview" que integre el hecho del pensamiento a la historia del universo. Saber leer el dinamismo escatológico del cosmos es saber leerlo en clave de transformación, mutación, metamorfosis, transfiguración, resurrección. El cristianismo aporta a la ciencia la "promesa de la gran metamorfosis" (De Lubac, 1967, p. 221), o sea, "el acabamiento del Cuerpo Místico [...] la realización perfecta del "Pleroma" (p. 222). Porque, en palabras de T. de Chardin, 
Eran necesarios nada menos que los trabajos tremendos y anónimos del hombre primitivo y la larga hermosura egipcia, y la espera inquieta de Israel, y el perfume lentamente destilado las místicas orientales, y la sabiduría cien veces refinada de los griegos para que sobre el árbol de Jesé y de la Humanidad pudiera brotar la Flor. Todas estas preparaciones eran cósmicamente, biológicamente, necesarias para Cristo hiciese su entrada en la escena humana (Citado en Haught, 2009, p. 68).

Como sugiere A. Peacocke, la teología tiene la capacidad de aprender del modo como la ciencia explora el mundo natural, a la vez que la teología aporta la justificación de toda la tarea científica. En otras palabras, la teología tiene una tarea a realizar en y con la ciencia evolutiva actual. Pues, agrega Haught (2014), la ciencia nos ofrece:

[...] el desarrollo de un drama cósmico en expectación, teniendo en cuenta los $14 \mathrm{mil}$ millones de años de historia natural y los cuatro billones de años de evolución de la vida, preńados de promesa que todavía se ha de revelar [...] La buena suerte de la teología actual es que la ciencia nos ha revelado un cosmos no terminado y todavía imperfecto (pp. 14-15).

La grandeza y el sentido o significado de la creación son escatológicos, están en el futuro. Estamos viviendo el paso de una teología fundada en una metafísica del eterno más-allá, a una metafísica del futuro, es decir, de una metafísica del pasado a una del futuro escatológico. Lo que significa también una nueva comprensión de la trascendencia, no ya la trascendencia espacial sino la temporal, no el otro mundo espacial sino el futuro. Como dice Chardin, Dios nos llama desde las profundidades del porvenir cósmico. Estamos inmersos en un dinamismo cósmico de futuro, pues Dios gobierna el mundo dirigiéndolo hacia el futuro.

Todavía vienen muchas sorpresas en el futuro del universo, pues "desde que comenzó a existir hace catorce mil millones de años, continuamente ha hecho sitio a logros nuevos e inauditos" (Haught, 2009, p.88). La creación aparece, no como un hecho del pasado, sino como una realidad del hoy y del futuro, en el que se dará su culminación: "new creation' eschatology”, dicen los teólogos de la ciencia y esta teología piensa las consecuencias cosmológicas, histórico-sociales y escatológicas de la Resurrección del 
Señor, que es el aguijón de la creación y de la historia. Esta nueva teología considera desde una perspectiva científica las realidades cristianas, pues dice Haught (2014): "la revolución darwiniana y la cosmología contemporánea nos llaman a un desarrollo de las doctrinas de creación, pecado y redención" (p. 41). No solo de la creación continua escatológica, que complementa la idea de la creatio ex nibilo y el pecado original, que aparece como la rebelión del hombre contra la obra creadora que Dios está realizando: "El pecado no es tanto una alteración de la integridad cósmica inicial cuanto el rechazo a escuchar la llamada de Dios y participar así en la obra creadora del mundo [...] Nuestro pecado original es el rechazo de nuestra vocación y dar la espalda a la llegada del futuro" (Haught, 2014, pp. 92, 112). Se plantea también una nueva visión de los Sacramentos desde la escatología, pues la tradicional ha estado ligada a una concepción estática del cosmos y de la naturaleza, propia de la cosmología aristotélica.

El Dios Trinitario, mirado desde la perspectiva de la escatología, y no el Dios sin tiempo de los griegos, teniendo en cuenta, como lo anota Polkinghorne, que el cristianismo ya había hecho estallar el ser estático de la metafísica griega al introducirle la doctrina trinitaria de una comunión vital de personas, para Haught la idea cristiana de un Dios que se encarna rechaza la idea de un Dios que crea a la manera de la causa eficiente aristotélica. De igual manera implica el paso de una eclesiología estática a una dinámico-escatológica, pues la Iglesia, como el hombre, es producto de la evolución cósmica.

La Iglesia está naciendo en un parto dramático de gozo y de dolor inmensos, así como también el nacimiento del cosmos es un drama gozoso y doloroso. Evidentemente también la antropología, que exige una nueva definición de la naturaleza humana y se exige una nueva concepción del sufrimiento y de la muerte, porque en su Pasión y en su Cruz, el Señor no solo asumió el sufrimiento de la historia sino también el sufrimiento cósmico. El cosmos, como el hombre, está amenazado por las fuerzas de la destrucción, del mal y de la muerte, pero la teología cristiana afirma que el universo no está abandonado en manos del azar y la entropía, pues como dice Haught (2009) "si el cristianismo es verdad, también el universo físico debe ser salvado" (p. 80 ), porque "Jesús y su obra redentora no pueden ser aislados de la red de relaciones naturales que le ligan $-\mathrm{y}$ nos ligan- al cosmos y su historia" (83). 
Así como la idolatría es adoración de la naturaleza, así también el mal es sometimiento o imitación de la naturaleza. Lo que es natural en el cosmos, el ser humano lo asume como decisión voluntaria en la historia. O sea, el mal humano es el mal del cosmos trasladado a la historia. La tendencia humana a la autodestrucción, a la inercia, al letargo y a la afirmación de la muerte es algo abrumador y desconcertante, que tiene raíces cósmicas. Por esto, la nueva teología plantea una nueva visión de la moral, no fundamentada ya en una metafísica del pasado y en un eterno presente, sino en la escatología, como respuesta o negación al proceso creador de Dios.

Es el paso de una moral estática a una moral dinámica. Sin la termodinámica, que es el estudio del intercambio de energías en los sistemas físicos y que se aplica universalmente a todo sistema físico y biológico, la evolución de la vida en la tierra hubiera sido imposible. Pero la termodinámica es fundamentalmente bivalente: está en lo que llamamos el mal natural y en lo que llamamos el bien natural. Russell escribió: Seremos libres de la tiranía de la entropía, y aparecerá el universo como la programada creación de Dios: ¿un nuevo cielo y una nueva tierra? Como cristiano, dice, su respuesta es sí. Esto significará que la nueva creación no incluirá la termodinámica, en la medida en que ella contribuye al mal natural, pero incluirá lo que contribuye al bien natural. El bien total de la creación no está en el presente, sino en su futuro escatológico (p. 28).

\section{LISTA DE REFERENCIAS}

Boersma, H. (2009). Nouvelle Théologie and sacramental ontology. Oxford: Oxford Univ. Press.

De Lubac, Henri. (1967). El pensamiento religioso de Teilhard de Chardin. Madrid: Taurus.

Haught, J. F. (2009). Cristianismo y ciencia. Hacia una teología de la naturaleza. Santander: Sal Terrae.

(2015). Resting on the future. Catholic theology for an Unfinished Universe. New York: Bloomsbury. 
McCool, G. A. (1989a). Nineteenth-century Scholasticism: The search for a Unitary Method. USA: Fordham university press. (1989b). From Unity to Pluralism: the internal revolution of Thomism. New York: Fordham Univ. Press.

Metz, J.B. (1972). Antropocentrismo cristiano. Sobre la forma del pensamiento de Tomás de Aquino. Salamanca: Ed. Sígueme.

Milbank, J. (2004). Teología y teoría social. Más allá de la razón secular. Barcelona: Herder.

. (2005). The Suspended Middle. Henri de Lubac and the Debate cconcerning the Supernatural. Michigan/Cambridge: W.B. Eardmans Publ. Comp. Grand Rapids.

Mongrain, K. (2002). The systematic thought of Hans Urs von Balthasar. New York: The Crossroad Pub. Comp.

Newman, J. H. (1997). Ensayo sobre el desarrollo de la doctrina cristiana. Salamanca: Bibliotec Oecumenica Salmanticensis.

Peacocke, A. (2008). Los caminos de la ciencia hacia Dios. El final de toda nuestra exploración. Santander: Sal Terrae.

Polkinghorne, J. (2000). Ciencia y Teología. Una introducción. Santander: Sal Terrae.

Russell, R. J. (2002). Bodily Resurrection, Eschatology and Scientific Cosmology: The mutual interaction of Christian Theology and Science. En Ted Peters, Robert John Russell and Michel Welker. (Eds.). Resurrection: Theological and Scientific Assessments. Grand Rapids: Eardmans Publishing Company.

Von Balthasar, Hans U. (1939). Patristik, Scholastik und wir. En Theologie der Zeit.

Vorgrimler, H. (1988). Entender a Karl Rahner. Introducción a su vida y pensamiento. Barcelona: Herder. 